\title{
Intensive liquid feeding of dairy calves with a medium crude protein milk replacer: Effects on performance, rumen, and blood parameters
}

\author{
M. R. de Paula, C. E. Oltramari, J. T. Silva, M. P. C. Gallo, G. B. Mourão, and C. M. M. Bittar ${ }^{1}$ \\ Department of Animal Sciences, "Luiz de Queiroz" College of Agriculture, University of São Paulo, Piracicaba, 13418-900, Brazil
}

\section{ABSTRACT}

The objective of this study was to evaluate the effects of different liquid-feeding systems using a medium crude protein milk replacer on performance, rumen, and blood parameters. Thirty newborn Holstein calves were blocked according to birth weight and date of birth, and randomly distributed to different liquid-feeding systems: conventional $(4 \mathrm{~L} / \mathrm{d})$, intensive $(8 \mathrm{~L} / \mathrm{d})$, or stepup/step-down (wk 1, $4 \mathrm{~L} / \mathrm{d}$; wk 2 to $6,8 \mathrm{~L} / \mathrm{d}$; wk 7 and $8,4 \mathrm{~L} / \mathrm{d})$. The commercial milk replacer $(12.5 \%$ solids, $20.2 \%$ crude protein, $15.6 \%$ fat) was fed twice daily $(0700$ and $1700 \mathrm{~h})$ until calves were weaned, at $8 \mathrm{wk}$ of age. Calves were individually housed in wood hutches, with free access to water and starter concentrate, and to hay only after weaning. They were followed through 10 wk of age. Milk replacer and starter intake were inversely affected by feeding system. After weaning, starter intake and hay intake were similar among feeding systems. Total dry matter intake was higher during the liquid-feeding period for calves on the intensive system compared to calves on the conventional system, but conventional feeding resulted in the highest dry matter intake after weaning. Feed efficiency was similar among feeding systems before and after weaning. Average body weight and daily gain were not affected by feeding system before or after weaning. During liquid feeding, diarrhea occurrence was lower for calves on the conventional system; however, when calves on the stepup/step-down system were fed lower volumes of liquid feed, diarrhea occurrence was similar to that of calves on the conventional system. Plasma concentrations of $\beta$-hydroxybutyrate were higher for calves on the conventional system, reflecting starter intake. Rumen $\mathrm{pH}$, short-chain fatty acids, and $\mathrm{N}-\mathrm{NH}_{3}$ were not affected by feeding system. Feeding higher volumes of milk replacer with a medium crude protein content had no beneficial effect on the performance of calves up to $10 \mathrm{wk}$ of age. Key words: starter intake, weaning, rumen development, fecal score, weight gain

Received January 5, 2016.

Accepted February 11, 2017.

${ }^{1}$ Corresponding author: carlabittar@usp.br

\section{INTRODUCTION}

Recent research in dairy calves has investigated management and nutrition improvements to benefit future productivity. The literature shows that feeding higher volumes of liquid diet for dairy calves results in higher daily gain and may increase future milk production (Heinrichs and Heinrichs, 2011; Soberon and Van Amburgh, 2013). For this reason, producers are slowly shifting from a restricted feeding system (conventionally $4 \mathrm{~L} / \mathrm{d}$ ) to systems that include higher volumes of liquid diet. The main objective of conventional feeding is to stimulate intake of starter concentrate, which promotes rumen development and allows for early weaning without reduced performance. As well, conventional feeding may lower rearing costs, which is attractive to some milk production systems (Davis and Drackley, 1998). However, although it is possible to attain satisfactory performance with conventional feeding systems, the opportunity to increase future milk production is lost.

Intensive feeding systems lead to higher daily gains, and increased intake of nutrients from the liquid portion of the diet results in higher feed efficiency (Blome et al., 2003). However, this system requires higher CP content in the milk replacer as a way of modulating the composition of the gain, with higher proportions of protein and water and less fat. Animals are heavier when they are weaned, but with a lower percentage of body fat (Kertz and Loften, 2013). The benefits of intensive liquid feeding for future milk production have been consistently observed with milk replacer that contains $28 \%$ CP and 15 or $20 \%$ fat (Soberon et al., 2012). However, this type of milk replacer is not always available. In Brazil, for example, the highest $\mathrm{CP}$ content in commercial milk replacer is $23 \%$, which may be a problem for producers who adopt intensive liquid-feeding systems (Silva and Bittar, 2013).

Another problem for the adoption of intensive feeding is the reduction in concentrate intake, which delays rumen development and hinders weaning. As well, some of the growth advantage realized with intensive feeding may be lost after weaning, because calves are not prepared to maintain growth solely from solid feed (Bach et al., 2013). For this reason, a gradual reduction in 
the volume of liquid feed in the last weeks before weaning (step-down system) has been presented as good strategy for stimulating concentrate intake, facilitating weaning, and preventing performance reduction.

The objective of this study was to evaluate the effects of different liquid-feeding systems (conventional, intensive, and step-down; 20\% CP milk replacer; abruptly weaned at 8 wk of age) on performance, rumen activity, and blood parameters in calves up to $10 \mathrm{wk}$ of age.

\section{MATERIALS AND METHODS}

All procedures with animals were in accordance with the ethical standards of the University of São Paulo and approved by the Ethics Committee on Animal Experimentation (CEUA/ESALQ) before the beginning of the study. The study was conducted in the Experimental Calf System of the Animal Science Department at "Luiz de Queiroz" College of Agriculture, University of São Paulo, Piracicaba, SP, Brazil, from May to September 2011. Thirty newborn male Holstein calves (birth weight $39.7 \pm 3.4 \mathrm{~kg}$ ) were used in a completely randomized block experimental design. Calves were blocked according to birth weight and date of birth (10 blocks), so that weight and age were homogeneous within each block. Groups of about 10 calves were transported $(95 \mathrm{~km})$ from a commercial dairy farm to the calf facility, at 3 to $5 \mathrm{~d}$ of age, in a cattle truck with straw bedding. Calves were separated from their mothers and fed at least $2 \mathrm{~L}$ of high-quality colostrum just after birth and $12 \mathrm{~h}$ later. Calves were fed $4 \mathrm{~L} / \mathrm{d}$ of transition milk until they were transported. At the calf facility, calves were individually housed in wood shelters in a grassy field. They were fed a commercial milk replacer (Sprayfo Violeta, $12.5 \%$ solids, $20.2 \%$ CP, $15.6 \%$ fat; Sloten do Brazil Ltd., Santos, SP, Brazil) twice daily (0700 and $1700 \mathrm{~h}$ ), and had free access to water and a pelleted commercial starter concentrate (Table 1). Animals were randomly distributed to one of the liquid-feeding systems: conventional $(4 \mathrm{~L} / \mathrm{d})$, intensive $(8 \mathrm{~L} / \mathrm{d})$, or step-up/step-down (SUSD; wk 1, $4 \mathrm{~L} / \mathrm{d}$; wk 2 to $6,8, \mathrm{~L} / \mathrm{d}$; wk 7 and $8,4 \mathrm{~L} / \mathrm{d}$ ). Animals were abruptly weaned, regardless of starter concentrate intake, at the end of wk 8. Pelleted commercial starter was fed ad libitum every morning, and orts were weighed to monitor daily intake. Starting on the weaning day, calves received coast-cross hay [Cynodon dactylon (L.) pers.] ad libitum in a bucket, and orts were measured once per week. Animals were weighed weekly, before the morning milk feeding, on a mechanical scale (ICS-300; Coimma Ltd., Dracena, SP, Brazil), and wither height, heart girth, and hip width were also measured. Every morning, calves were examined for diarrhea, receiving a score of 0 (no diarrhea) or 1 (diarrhea).
Blood samples were taken weekly, $2 \mathrm{~h}$ after the morning feeding, via jugular venipuncture by vacuum tubes containing sodium fluoride and potassium EDTA (Vacuette of Brazil, Campinas, SP, Brazil). Samples were centrifuged (Universal 320R; Hettich, Tuttlinger, Germany) at 2,000 $\times g$ for $20 \mathrm{~min}$ at $4^{\circ} \mathrm{C}$, and plasma was stored in a freezer $\left(-26^{\circ} \mathrm{C}\right)$ until analysis. Specific commercial enzymatic kits were used to analyze plasma glucose (Glicose HK Liquiform; Labtest Diagnóstica S.A., Lagoa Santa, MG, Brazil) and BHB concentrations (RANBUT; Randox Laboratories, Life Sciences Ltd., Crumlin, United Kingdom) in an automatic biochemical system (SBA-200; CELM, Barueri, SP, Brazil).

Two hours after morning feeding, ruminal fluid samples were collected at wk 4, 8, and 10 of age using an oroesophageal tube and a vacuum pump (TE-0581; Tecnal Ltda., Piracicaba, SP, Brazil), taking care to avoid saliva contamination. Samples $(50 \mathrm{~mL})$ were filtered through cheesecloth, and $\mathrm{pH}$ was measured immediately (DMPH-2; DIGIMED, Campo Grande, MS, Brazil). Samples were frozen approximately 20 min after collection for subsequent short-chain fatty acid (SCFA) analysis. Samples were then thawed and centrifuged (Universal 320R; Hettich) at 15,000 $\times \mathrm{g}$ at $4^{\circ} \mathrm{C}$ for 60 min to obtain the supernatant, as described by Ferreira et al. (2009). Samples were analyzed by liquid gas chromatograph (5890 Series II GC; Hewlett Packard, Wilmington, DE) equipped with an integrator (3396 Series II Integrator; Hewlett Packard) and an automatic injector (6890 Series Injector; Hewlett Packard). A volume of $100 \mu \mathrm{L}$ of the internal standard (2-methylbutyric acid), $800 \mu \mathrm{L}$ of sample, and $200 \mu \mathrm{L}$ of formic acid were pipetted into a vial for gas chromatograph injection. A mixture of SCFA of known concentration was the external standard for calibration. To determine ${\mathrm{N}-\mathrm{NH}_{3}}_{3}$, a rumen sample was centrifuged $\left(11,000 \times g, 4^{\circ} \mathrm{C}, 30 \mathrm{~min}\right)$ to obtain the

Table 1. Milk replacer and solid feed chemical composition (\% of DM)

\begin{tabular}{lccc}
\hline Item & $\begin{array}{c}\text { Milk } \\
\text { replacer }\end{array}$ & Concentrate $^{2}$ & $\begin{array}{c}\text { Coast- } \\
\text { cross hay }\end{array}$ \\
\hline DM, \% & 97.4 & 89.2 & 92.2 \\
Ash & 8.2 & 8.1 & 5.2 \\
CP & 20.2 & 21.6 & 6.8 \\
Ether extract & 15.6 & 3.4 & 1.6 \\
NDF & 0.5 & 28.0 & 77.6 \\
ADF & - & 10.2 & 41.26 \\
NFC $^{3}$ & 55.5 & 38.9 & 8.8 \\
TDN $^{4}$ & - & 72.9 & 52.3 \\
\hline
\end{tabular}

${ }^{1}$ Sprayfo Violeta (Sloten do Brasil Ltda., Santos, SP, Brazil).

${ }^{2}$ Rumina 18P (Guabi Nutrição Animal, Campinas, SP, Brazil).

${ }^{3} \mathrm{NFC}=100-(\mathrm{CP}+$ ether extract $+\mathrm{NDF}$ free of $\mathrm{CP}+\mathrm{ash})$

${ }^{4}$ Calculated according to Weiss (1993). 
supernatant and analyzed according to Chaney and Marbach (1962), adapted for absorbance reading with an automatic biochemical analyzer (SBA-200; CELM) using a 540-nm filter.

Milk replacer, starter, and hay samples were taken monthly and ground through a $1 \mathrm{~mm}$ mesh for analysis (Table 1). Determinations of DM, ash, and ether extract (EE) were done according to the procedures of the Association of Official Analytical Chemists (AOAC, 1990). Crude protein was analyzed by combustion, according to the Dumas method (Etheridge et al., 1998), with an N analyzer (FP-528; LECO, St. Joseph, MI). Free-ash NDF was determined, according to the method of Van Soest et al. (1991), using sodium sulfite and thermostable amylase. Values of total digestible nutrients (TDN) were calculated by the equations proposed by Weiss (1993) and NFC according to the equation $\mathrm{NFC}=100-(\mathrm{CP}+\mathrm{EE}+\mathrm{NDFcp}+$ ashes $)$, where NDFcp was NDF free of CP.

Diarrhea occurrence was analyzed as a variable with a binomial distribution (0 for absence and 1 for presence) with a logit link function using the PROC GLIMMIX of SAS (SAS Institute Inc., 2013). Daily feed intake data were averaged for each week before statistical analysis. Continuous data were analyzed as a randomized complete block design with repeated measures using the PROC MIXED of SAS. For both analyses, the following model was used: $Y_{i j k}=\mu+T_{i}+B_{j}$ $+A_{k}+W_{i j}+T_{i k}+E_{i j k}$, where $Y_{i j k}$ was the response variable; $\mu$ was the overall mean; $T_{i}$ was the treatment effect (liquid-feeding system); $\mathrm{B}_{\mathrm{j}}$ was the random block effect; $A_{k}$ was the animal's age effect; $W_{i j}$ was the error associated with the calf; $\mathrm{TA}_{\mathrm{ik}}$ was the effect of the interaction of treatment and age; and $\mathrm{E}_{\mathrm{ijk}}$ was the residual effect. For means comparison, a Student's $t$-test was used. Means were estimated using least squares means. Significance was declared for values of $P<0.05$, and trends for values $0.05<P<0.10$ for all parameters.

\section{RESULTS AND DISCUSSION}

Liquid-feeding system affected milk replacer intake $(P<0.0001)$; we observed higher intake for calves on the intensive system, intermediate intake for calves on the SUSD system, and lower intake for calves on the conventional system (Table 2). As expected, we observed an age effect for milk replacer intake $(P<$ 0.0001), because for calves fed on the SUSD system consumed different volumes during the liquid-feeding period. Milk replacer intake for calves on the intensive system was lower than the volume fed $[8 \mathrm{~L} / \mathrm{d}$ or $974 \mathrm{~g}$ of milk solids (MS)/d], suggesting a plateau of intake when calves are fed in only 2 feedings. We observed maximum intake from wk 7 of age, when calves consumed $7.8 \mathrm{~L} / \mathrm{d}(950 \mathrm{~g}$ of $\mathrm{MS} / \mathrm{d})$. This intake plateau was corroborated by calves in the SUSD system, which also consumed less than $974 \mathrm{~g}$ of MS/d during the period of higher feeding volume (wk 2 to wk 6). However, for animals on the conventional system, we observed lower milk replacer intake during the first 3 wk $(3.7 \mathrm{~L} / \mathrm{d}$ or $450.5 \mathrm{~g}$ of MS/d), when these calves had higher occurrence of diarrhea. Other authors have also reported a milk replacer intake plateau (Silper et al., 2014), decreasing total planned intake. This problem could be solved with strategies such as an increase in solids, a higher number of feedings, or feeding formulas with higher nutrient concentration.

Table 2. Preweaning and postweaning performance of dairy calves on a conventional (CON), intensive (INT), or step-up/step-down (SUSD) liquid-feeding program

\begin{tabular}{|c|c|c|c|c|c|c|c|}
\hline Item & \multicolumn{3}{|c|}{ Program } & SEM & \multicolumn{3}{|c|}{$P$-value } \\
\hline Milk-replacer intake, $\mathrm{g}$ of $\mathrm{DM} / \mathrm{d}$ & $486.4^{\mathrm{c}}$ & $896.6^{\mathrm{a}}$ & $736.8^{\mathrm{b}}$ & 13.0 & $<0.0001$ & $<0.0001$ & $<0.0001$ \\
\hline Concentrate intake, $\mathrm{g}$ of $\mathrm{DM} / \mathrm{d}$ & $362.1^{\mathrm{a}}$ & $100.0^{\mathrm{b}}$ & $189.7^{\mathrm{b}}$ & 31.4 & $<0.0001$ & $<0.0001$ & $<0.0001$ \\
\hline $100 \mathrm{~g}$ concentrate intake, $\mathrm{d}$ & $21.5^{\mathrm{b}}$ & $31.1^{\mathrm{a}}$ & $19.9^{\mathrm{b}}$ & 2.5 & 0.0079 & - & - \\
\hline Feed efficiency & 0.316 & 0.341 & 0.330 & 0.037 & 0.8960 & $<0.0001$ & 0.0972 \\
\hline \multicolumn{8}{|l|}{ Postweaning } \\
\hline Total intake, $\mathrm{g}$ of $\mathrm{DM} / \mathrm{d}$ & $2,055.9^{\mathrm{a}}$ & $1,740.4^{\mathrm{b}}$ & $1,698.9^{\mathrm{b}}$ & 97.4 & 0.0280 & $<0.0001$ & 0.0584 \\
\hline Concentrate intake, $\mathrm{g}$ of $\mathrm{DM} / \mathrm{d}$ & $1,643.1$ & $1,415.8$ & $1,560.2$ & 74.4 & 0.3682 & 0.0741 & 0.3305 \\
\hline Hay intake, $g$ of DM/d & 412.8 & 327.3 & 138.8 & 86.2 & 0.0836 & $<0.0001$ & 0.0321 \\
\hline Average BW, kg & 66.3 & 66.0 & 65.4 & 2.8 & 0.9327 & $<0.0001$ & 0.2223 \\
\hline Average weight gain, g/d & 935.8 & 810.2 & 876.0 & 59.2 & 0.2063 & 0.0007 & 0.0431 \\
\hline
\end{tabular}

\footnotetext{
${ }^{a-c}$ Values in the same row with different superscript letters differed $(P<0.05)$.
} 


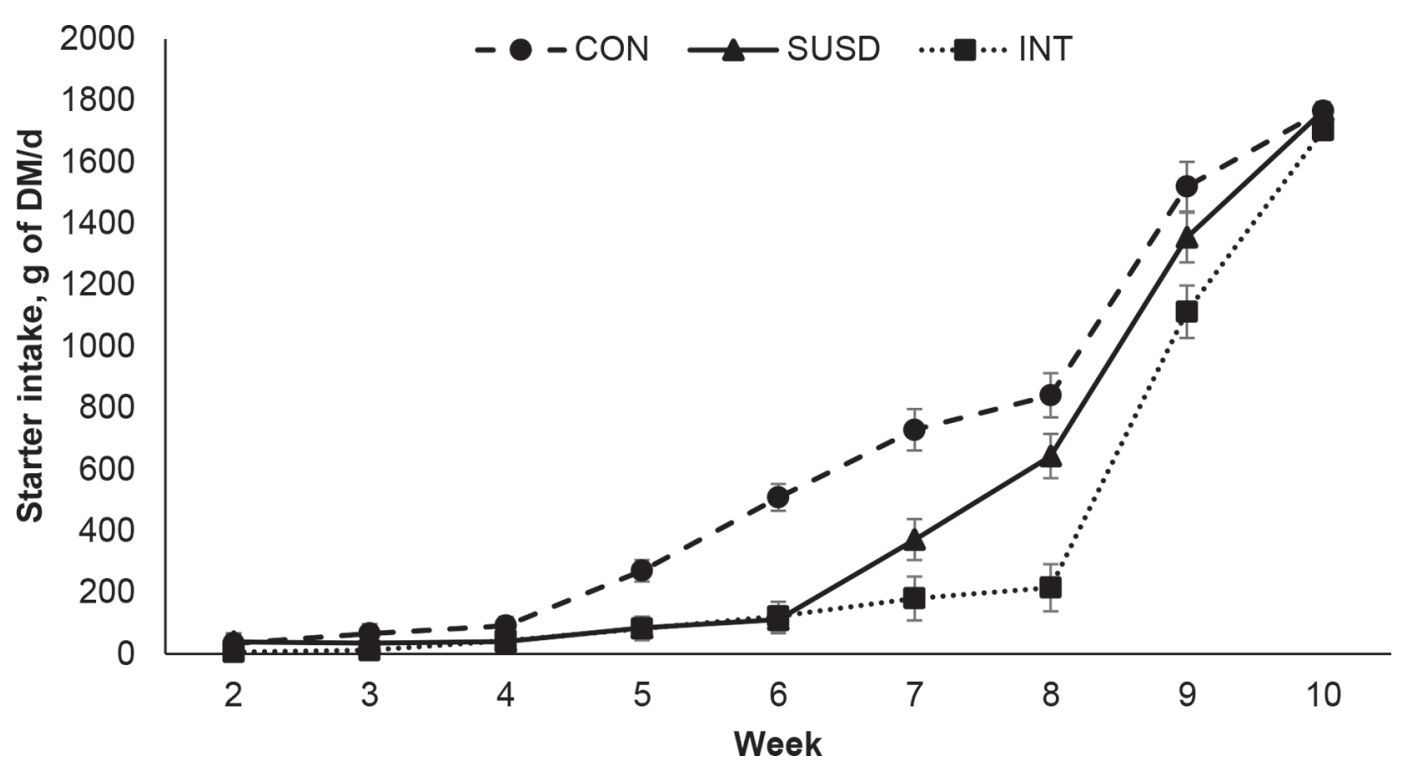

Figure 1. Starter intake (error bars indicate SEM) of dairy calves in conventional (CON, 4 L/d), step-up/step-down (SUSD, 4 L/d to 8 L/d to $4 \mathrm{~L} / \mathrm{d}$ ), or intensive (INT, $8 \mathrm{~L} / \mathrm{d}$ ) milk-feeding programs.

A simulation presented by Kertz and Loften (2013) similar to that experienced by the calves on the conventional feeding system in the present study - demonstrated that animals consuming approximately 460 g of milk replacer/d with $20 \% \mathrm{CP}$ and $20 \%$ EE would not have enough protein for lean tissue growth, and the additional energy would be converted to fat. The authors indicated that better results could be obtained by providing higher volumes of milk replacer that included CP levels above $20 \%$.

Liquid-feeding system also affected starter concentrate intake during the preweaning period $(P<0.0001)$; we observed higher average intake for calves on the conventional system (Table 2). High milk replacer intake resulted in lower starter concentrate intake during the preweaning period, and this led to inadequate solid feed intake for weaning at wk 8 (Figure 1). Because starter intake is inversely correlated with milk replacer intake, we observed a significant interaction between liquidfeeding systems and calf age $(P<0.0001)$, mainly because of the SUSD system (Figure 1). However, after weaning, starter intake was similar for all liquid-feeding systems $(P>0.05)$; we observed rapid increases for calves fed according to systems with lower intake during preweaning (Figure 1). At the end of the evaluation period, all calves had similar starter concentrate intake, demonstrating that although calves on the intensive system did not have adequate starter intake at weaning, starter intake increased rapidly (Figure 1). It took $14 \mathrm{~d}$ for calves on the intensive system to reach the same intake as calves on the convention system; however, this difference was not accompanied by decreased weight gain. On the other hand, total DMI was lower for calves fed more milk replacer, possibly a result of reduced rumen development.

Recent studies have recommended that calves consume at least $1 \mathrm{~kg}$ of starter concentrate at weaning to maintain ADG postweaning (Stamey et al., 2012). At weaning, calves on the conventional system had starter intake of approximately $800 \mathrm{~g} / \mathrm{d}$, similar to that suggested by Quigley (1996) as being adequate for weaning dairy calves, considering starter effects on rumen development. As calves age and nutrient requirements increase, lower intake of milk replacer stimulates starter intake. An increase in starter intake has a positive effect on rumen development (Kristensen et al., 2007) and allows animals to maintain performance after weaning. For animals on the SUSD system, we observed an increase in starter intake by wk 6 (Figure 1) when milk-replacer feeding was reduced, demonstrating that SUSD is a promising strategy for weaning calves that receive higher volumes of liquid feed.

The time required for calves on the intensive system to reach $100 \mathrm{~g}$ of starter concentrate intake was $31.1 \mathrm{~d}$ $(P=0.0079)$, approximately $10 \mathrm{~d}$ longer than for the other liquid-feeding systems. This finding demonstrates that even though starter intake was very low during the first month of life, regardless of liquid-feeding system, calves fed higher volumes of milk replacer took longer to show expressive starter intake. The literature recommends that weaning decisions should consider starter intake (Roth et al., 2009), a progressive reduction in liquid feed supply (Khan et al., 2007), or higher liquidfeeding periods to guarantee adequate performance 
after weaning. However, we observed no differences among feeding systems on performance in the postweaning period, despite the fact that starter intake was not consider as a criteria for weaning (Table 2).

We observed a tendency $(P=0.0836)$ for higher hay intake among calves on the conventional system, and this contributed to the higher total DMI $(P<0.03)$ observed postweaning for calves fed on this system (Table 2). Hay was fed only after weaning, because fiber digestion is limited during the liquid-feeding period, and the accumulation of undigested material in the rumen may negatively influence starter intake (Khan et al., 2011a). Nevertheless, feeding hay after weaning is important to keep a favorable ruminal environment, increasing the number of SCFA transporters by 4 times (Castells et al., 2013). The tendency for higher hay intake among calves on the conventional system also suggests that these animals had a more developed rumen, capable of using feeds with high fiber content.

During the preweaning period, total DMI was significantly higher $(P=0.0359)$ for calves on the intensive system (Table 2), because of the nutrition plane calves were submitted to. However, after weaning, DMI was higher $(P=0.0280)$ for calves on the conventional system, because of higher starter and hay intake compared with the other systems, proving that animals on the conventional system were more ready to be weaned. We know that DMI is highly correlated with animals' future performance, and according to Heinrichs and Heinrichs (2011), each increase of $1 \mathrm{~kg}$ in DMI after weaning is followed by an increase of $290 \mathrm{~kg}$ of milk produced during the first lactation. On the other hand, feeding high volumes of liquid diet may also improve future lactation performance (Soberon et al., 2012), so a combination of high-volume feeding and strategies to increase postweaning DMI must be pursued.

Body weight was not affected by liquid-feeding system $(P=0.4147)$, but we did observe an age effect $(P<0.0001)$ with increasing values. Although DMI was higher for calves on the intensive system, similar ADG resulted in similar BW (Table 2). Our results suggest that the low $\mathrm{CP}$ content in the milk replacer formula limited the growth rate of calves on the intensive system. In a study by Bascom et al. (2007), calves fed a milk replacer containing $20 \% \mathrm{CP}$ had lower performance than calves fed a milk replacer containing 27 or $30 \% \mathrm{CP}$. These authors reported that feeding a 20:20 (CP:EE) milk replacer at a 15\% BW rate resulted in modest $\mathrm{ADG}$, as we observed in the present study.

After weaning, BW was similar among feeding systems $(P=0.9327)$. Despite the lower starter intake for calves on the intensive and SUSD systems, all animals reached a similar BW by the end of the evaluation pe- riod (Table 2). However, the 2 wk of postweaning evaluation may have been too short to show performance reduction related to lower DMI during this feeding phase. Other authors have suggested that animals fed intensively should have an ADG of 750 to $800 \mathrm{~g} / \mathrm{d}$ (Davis and Drackley, 1998; Khan, et al., 2011a; Soberon, et al., 2012), allowing animals to double their birth weight within 56 d. However, we did not observe this growth rate, or a doubling of the animals' birth weight.

Although ADG was not different among liquid-feeding systems $(P=0.7862)$, it was variable during the first weeks, when the occurrence (number of days with diarrhea/7 d) of diarrhea was higher. These variations resulted in an interaction between feeding strategy and age $(P<0.05$; Table 2$)$, with a reduction in ADG during wk 6 for animals on the SUSD system $(P<$ $0.05)$, because of the planned reduction in liquid feed. Although starter intake increased because of the liquidfeed reduction, the increase was not enough to maintain growth rate.

A meta-analysis by Soberon and Van Amburgh (2013) showed that animals on conventional feeding systems have ADG of 250 to $400 \mathrm{~g}$, corroborating the results of the present study. However, those authors also reported ADG 600 and $800 \mathrm{~g} / \mathrm{d}$ for intensively fed calves, higher than the ADG observed in the present study. The literature shows that animals on intensive systems have higher performance and feed efficiency when milk replacer $\mathrm{CP}$ is $>22 \%$ and energy content is adequate (Blome et al., 2003; Bascom, et al., 2007). In the present study, the $\mathrm{CP}$ and the energy content could have limited calves' performance among those fed $8 \mathrm{~L} / \mathrm{d}$ during all periods.

After weaning, ADG was not affected by liquid-feeding system $(P=0.2063)$, and it rose as animals aged, because of the increase in starter intake. Even with the lower starter intake, calves on the intensive system had no performance reduction because of weaning. Instead, animals increased their starter intake after weaning, reaching similar BW at the end of the evaluation period. These results were in contrast to those of Bach et al. (2013), who concluded that animals struggled to adapt to a new diet and ended up losing weight.

Feed efficiency was not affected by liquid-feeding system before weaning $(P=0.89)$ or after $(P=0.28)$. This was an important result, because calves on the conventional system, which consumed more DM from concentrate, presented a feed efficiency that was similar to the others. According to Davis and Drackley (1998), this is beneficial for weaning, because when animals start to receive only a solid diet, management and feeding costs decrease. These results were unexpected and lower than those in the literature for calves fed on 
Table 3. Body measurements of dairy calves on a conventional (CON), intensive (INT), or step-up/step-down (SUSD) liquid-feeding program

\begin{tabular}{|c|c|c|c|c|c|c|c|}
\hline Measure & \multicolumn{3}{|c|}{ Program } & SEM & \multicolumn{3}{|c|}{$P$-value } \\
\hline Gain, cm/wk & 0.97 & 1.04 & 0.90 & 0.06 & 0.11 & $<0.0001$ & 0.06 \\
\hline \multicolumn{8}{|l|}{ Heart girth } \\
\hline Average, cm & $84.3^{\mathrm{b}}$ & $87.2^{\mathrm{a}}$ & $86.2^{\mathrm{a}, \mathrm{b}}$ & 1.1 & 0.01 & $<0.0001$ & 0.11 \\
\hline \multicolumn{8}{|l|}{ Hip width } \\
\hline Average, cm & 23.1 & 23.8 & 23.4 & 0.4 & 0.13 & $<0.0001$ & 0.32 \\
\hline Gain, cm/wk & 0.38 & 0.43 & 0.36 & 0.02 & 0.07 & $<0.0001$ & 0.29 \\
\hline
\end{tabular}

${ }^{\mathrm{a}, \mathrm{b}}$ Values in the same row with different superscript letters differed $(P<0.05)$.

an intensive system; however, other studies used milk replacers with a higher CP content (Hill et al., 2006).

Animals on the intensive system had higher heart girth compared to animals on the conventional system $(P=0.01)$, but we observed no differences for other body measurements $(P>0.05$; Table 3$)$. Stamey et al. (2012) also observed that animals fed higher volumes of milk replacer had higher heart girth and higher height at withers compared with animals on a conventional system. Because animals were growing, we observed a significant age effect $(P<0.0001)$ for all body measurements (Table 3 ).

Liquid-feeding system affected diarrhea occurrence and odds ratio (Table 4) during the preweaning period, with higher occurrence for animals on the intensive and SUSD systems until wk $6(P<0.05)$. After that, when liquid feed volume was reduced for calves on the SUSD system, diarrhea occurrence was similar to that of calves on the conventional system. During this period, calves on the intensive system had 6.10 and 4.89 higher chances of diarrhea than SUSD calves for wk 7 and 8, respectively (Table 4), corroborating findings from Hill et al. (2006) and Stamey et al. (2012) that the volume fed affects feces fluidity.
Because the liquid-feeding systems affected solid intake, we expected differences in rumen development. However, the system had no effect on rumen $\mathrm{pH}$ value $(P=0.91$; Table 5$)$, which decreased as animals aged $(P=0.0004)$. Average values in wk $4(5.76 \pm 0.08)$ were higher than those in wk $8(5.43 \pm 0.08)$ and wk $10(5.23 \pm 0.08)$, respectively. The $\mathrm{pH}$ drop occurred because of the increase in starter concentrate intake and the consequent production of acids such as lactate, acetate, propionate, and butyrate by microbial feed fermentation (Davis and Drackley, 1998). Although calves were fed hay, $\mathrm{pH}$ decreased after wk 4 of age, because most of the DMI consisted of starter and not forage, varying from $8 \%$ of total intake for calves on the intensive system to $20 \%$ for calves on the conventional system. The decrease in rumen $\mathrm{pH}$ was similar to that observed by Lesmeister and Heinrichs (2004) with conventional liquid feeding and by Kristensen et al. (2007), who compared intensive and conventional liquid feeding. However, Silper et al. (2014) found higher values than shown in this study for intensively fed calves, also individually housed in a grassy field, which, according to the authors favored the establishment of ruminal fermentation, rumination, and maintenance of more de-

Table 4. Diarrhea occurrence and odds ratio of diarrhea in dairy calves on a conventional (CON), intensive (INT), or step-up/step-down (SUSD) liquid-feeding program

\begin{tabular}{|c|c|c|c|c|c|c|}
\hline Week & \multicolumn{3}{|c|}{ Diarrhea occurrence $^{1}$} & \multicolumn{3}{|c|}{ Diarrhea odds ratio ${ }^{2}$} \\
\hline 4 & $0.13 \pm 0.065^{\mathrm{a}}$ & $0.45 \pm 0.108^{\mathrm{b}}$ & $0.78 \pm 0.082^{\mathrm{c}}$ & 5.30 & 23.24 & 0.23 \\
\hline 5 & $0.13 \pm 0.066^{\mathrm{a}}$ & $0.37 \pm 0.104^{\mathrm{b}}$ & $0.69 \pm 0.094^{\mathrm{c}}$ & 3.73 & 14.34 & 0.26 \\
\hline 6 & $0.03 \pm 0.029^{\mathrm{a}}$ & $0.27 \pm 0.095^{\mathrm{b}}$ & $0.52 \pm 0.103^{\mathrm{b}}$ & 13.71 & 39.91 & 0.34 \\
\hline
\end{tabular}

${ }^{\mathrm{a}-\mathrm{C}}$ Values in the same row with different superscript letters differed $(P<0.05)$.

${ }^{1}$ Number of days with diarrhea/7 d (wk).

${ }^{2}$ Antilog of the difference between LSM from a linear mixed model analysis of logits. 
Table 5. Rumen fermentation parameters in dairy calves on a conventional (CON), intensive (INT), or step-up/step-down (SUSD) liquidfeeding program

\begin{tabular}{|c|c|c|c|c|c|c|c|}
\hline \multirow[b]{2}{*}{ Item } & \multicolumn{3}{|c|}{ Liquid-feeding program } & \multirow[b]{2}{*}{ SEM } & \multicolumn{3}{|c|}{$P$-value } \\
\hline & $\mathrm{CON}$ & INT & SUSD & & Program & Age & Program $\times$ Age \\
\hline \multicolumn{8}{|l|}{ Short-chain fatty acids, $\mu \mathrm{mol} / \mathrm{mL}$} \\
\hline Total & 106.6 & 105.4 & 112.5 & 6.44 & 0.70 & $<0.0001$ & 0.05 \\
\hline Acetate & 48.9 & 51.3 & 50.1 & 2.19 & 0.76 & 0.006 & 0.21 \\
\hline Propionate & 41.2 & 37.6 & 44.3 & 3.28 & 0.37 & $<0.0001$ & 0.02 \\
\hline
\end{tabular}

sirable $\mathrm{pH}$ values. The lower rumen $\mathrm{pH}$ observed in the present study may have been a result of the sampling time, which occurred $2 \mathrm{~h}$ after morning feeding, when starter concentrate was also fed. Calves usually ate all of the concentrate just after feeding, which led to a lower $\mathrm{pH}$ because of its high NFC composition (Table 1).

Total SCFA concentration was not affected by liquidfeeding system $(P=0.70$; Table 5$)$. However, the age effect was significant $(P<0.0001)$, with increasing concentrations after weaning, as also observed by Beharka et al. (1991). The interaction effect of age and feeding system was significant $(P=0.05)$, with lower concentrations at wk 8 for calves on the intensive system than for calves on the other systems, because of the lower starter intake in this particular week (Figure 1).

Individual SCFA concentrations were not affected by liquid-feeding system $(P>0.05)$, but increased as animals aged and consumed more starter concentrate $(P$ $<0.006$; Table 5). The increase in SCFA concentrations occurs because of the feed entry rate into the rumen, high feed fermentability, and posterior absorption by the rumen epithelium (Dijkstra et al., 1993). Propionic acid concentration was lower at wk 8 of age for calves fed on the intensive system $(P<0.02)$, again because of lower starter intake. These calves also had a tendency $(P=0.06)$ for lower butyric acid concentration than calves on the SUSD system at wk 8 of age. Geiger et al. (2014) reported that conventionally fed animals had higher acetic, propionic, and butyric acid concentrations than intensively fed calves. Propionic and butyric acid are responsible for rumen development stimuli, with respect to the number, height, and width of papillae (Beharka et al., 1998). Because of that, liquidfeeding systems that may delay rumen development should adopt adequate strategies to wean dairy calves.

Rumen concentrations of $\mathrm{N}^{-\mathrm{NH}_{3}}$ were not affected by liquid-feeding system $(P=0.94$; Table 5$)$. However, we observed a significant age effect $(P<0.005)$, with decreasing concentrations as animals aged, similar to results from Kristensen et al. (2007) and Lesmeister and Heinrichs (2004). As animals aged and rumen development occurred, we observed an increase in $\mathrm{N}^{-\mathrm{NH}_{3}}$ used by microbial populations or absorption through the rumen wall (Beharka et al., 1998).

Plasma glucose concentrations were not affected by liquid-feeding system $(P=0.32$; Figure 2$)$. Our observed values agreed with the literature for animals in conventional and intensive liquid-feeding systems (Blome et al., 2003). As expected, after weaning we observed a decrease in plasma glucose concentration $(P<0.0001)$ that was correlated with rumen development and the characteristic lower plasma glucose of functional ruminants. Low plasma glucose concentrations can trigger hunger signs, and increased concentrations result in satiety signals (Khan et al., 2011b). Thus, we expected that because of the higher lactose supply from milk replacer intake, calves on the intensive system would have higher plasma glucose concentrations, as observed by Cowles et al. (2006). Silper et al. (2014) observed plasma glucose concentrations even lower than results from the present study for intensively fed calves, suggesting that the milk replacer lactose contribution is not enough to promote adequate glycemia. However, even though plasma glucose concentrations were not higher for calves fed higher milk replacer volumes, their starter concentrate intake was lower, suggesting a satiety effect on the intensive system.

Plasma concentrations of BHB were affected by liquid-feeding system $(P<0.0001$; Figure 3$)$, following starter concentrate intake variation (Figure 1). Animals on the conventional system had higher BHB concentrations, followed by animals on the SUSD and intensive feeding systems $(0.15,0.12$, and $0.10 \mathrm{mmol} / \mathrm{L}$, respectively). As expected, we observed an age effect $(P<0.0001)$ for BHB concentrations, as a result of the increase in starter concentrate intake and consequent rumen development (Figure 3). Calves on the SUSD system had higher plasma BHB concentrations, mainly after wk 6 of age, when milk replacer feeding 


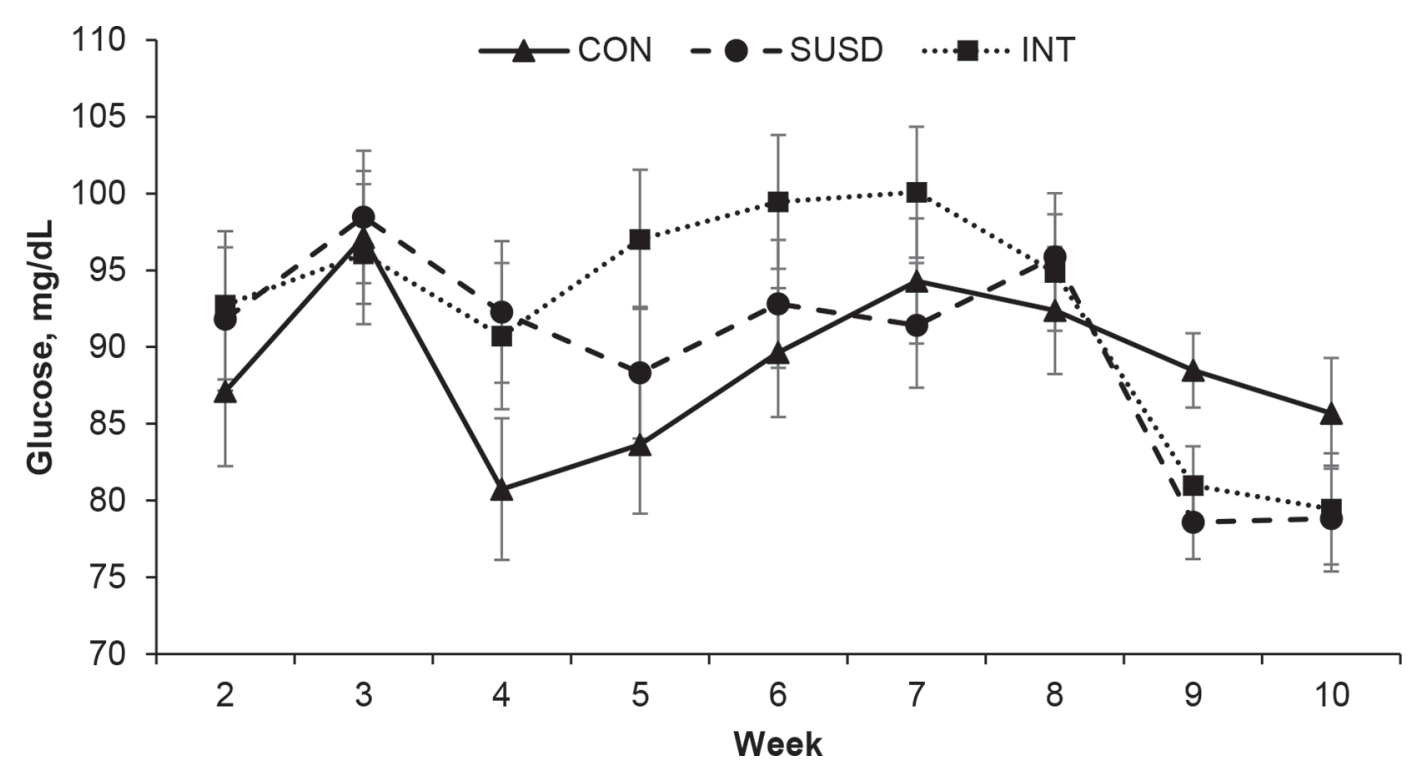

Figure 2. Plasma concentrations of glucose (error bars indicate SEM) of dairy calves in conventional (CON, 4 L/d), step-up/step-down (SUSD, $4 \mathrm{~L} / \mathrm{d}$ to $8 \mathrm{~L} / \mathrm{d}$ to $4 \mathrm{~L} / \mathrm{d}$ ), or intensive (INT, $8 \mathrm{~L} / \mathrm{d}$ ) milk-feeding programs.

was reduced and starter intake increased. According to Bach (2014), calves fed higher volumes of liquid diet may take time to consume starter concentrate, delaying rumen development. However, calves fed intensively started to consume concentrate starter in significant amounts immediately after weaning and had BHB plasma concentrations similar to animals on other feeding systems at $10 \mathrm{wk}$ of life.

\section{CONCLUSIONS}

Feeding higher volumes of a milk replacer with $20 \%$ $\mathrm{CP}$ and $15.6 \%$ fat had no positive effect on calves' performance. Rumen and blood parameters were affected by liquid-feeding system and calves' age, because of their effects on starter intake and resulting rumen development. We observed no performance or metabolic

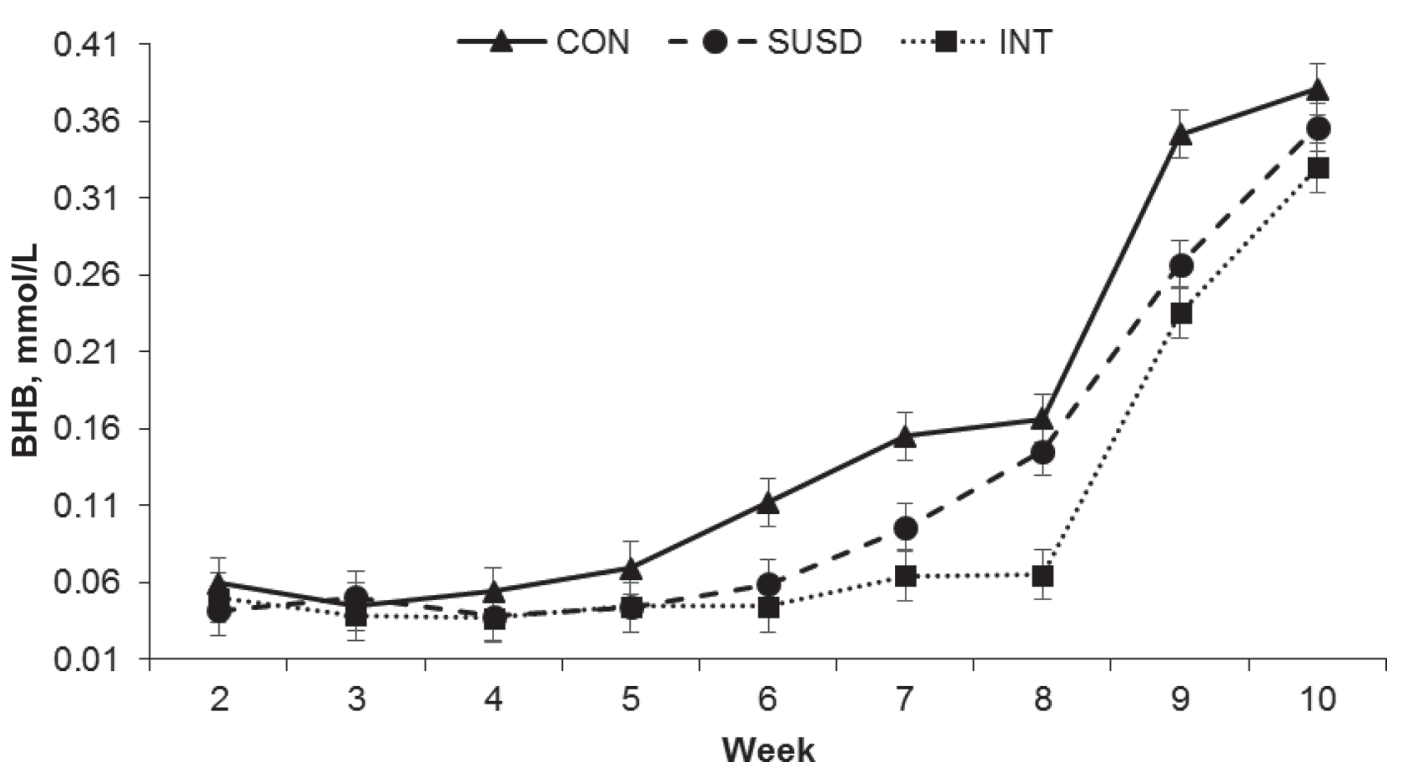

Figure 3. Plasma concentrations of BHB (error bars indicate SEM) of dairy calves in conventional (CON, 4 L/d), step-up/step-down (SUSD, $4 \mathrm{~L} / \mathrm{d}$ to $8 \mathrm{~L} / \mathrm{d}$ to $4 \mathrm{~L} / \mathrm{d}$ ), or intensive (INT, $8 \mathrm{~L} / \mathrm{d}$ ) milk-feeding programs. 
benefits from intensive feeding of a medium $\mathrm{CP}$ milk replacer.

\section{ACKNOWLEDGMENTS}

The authors express their appreciation for the financial support provided by the São Paulo Research Foundation (Fapesp 2010/16175-6).

\section{REFERENCES}

AOAC. 1990. Official Methods of Analysis. 15th ed. Vol. 1. AOAC Arlington, VA.

Bach, A. 2014. Effective forage and starter feeding strategies for preweaned calves. Adv. Dairy Technol. 26:153-163.

Bach, A., M. Terré, and A. Pinto. 2013. Performance and health responses of dairy calves offered different milk replacer allowances. J. Dairy Sci. 96:7790-7797.

Bascom, S. A., R. E. James, M. L. McGilliard, and M. Van Amburgh. 2007. Influence of dietary fat and protein on body composition of Jersey bull calves. J. Dairy Sci. 90:5600-5609.

Beharka, A. A., T. G. Nagaraja, and J. L. Morrill. 1991. Performance and ruminal function development of young calves fed diets with Aspergillus oryzae fermentation extract. J. Dairy Sci. 74:43264336.

Beharka, A. A., T. G. Nagaraja, J. L. Morrill, G. A. Kennedy, and R. D. Klemm. 1998. Effects of form of the diet on anatomical microbial, and fermentative development of the rumen of neonatal calves. J. Dairy Sci. 81:1946-1955.

Blome, R. M., J. K. Drackley, F. K. McKeith, M. F. Hutjens, and G. C. McCoy. 2003. Growth, nutrient utilization, and body composition of dairy calves fed milk replacers containing different amounts of protein. J. Anim. Sci. 81:1641-1655.

Castells, L., A. Bach, A. Aris, and M. Terré. 2013. Effects of forage provision to young calves on rumen fermentation and development of the gastrointestinal tract. J. Dairy Sci. 96:5226-5236.

Chaney, A. L., and E. P. Marbach. 1962. Modified reagents for determination of urea and ammonia. Clin. Chem. 8:130-132.

Cowles, K. E., R. A. White, N. L. Whitehouse, and P. S. Erickson. 2006. Growth characteristics of calves fed an intensified milk replacer regimen with additional lactoferrin. J. Dairy Sci. 89:48354845.

Davis, C. L., and J. K. Drackley. 1998. The Development, Nutrition, and Management of the Young Calf. Iowa State University Press, Ames.

Dijkstra, J., H. Boer, J. Van Bruchem, M. Bruining, and S. Tamminga. 1993. Absorption of volatile fatty acids from the rumen of lactating dairy cows as influenced by volatile fatty acid concentration, $\mathrm{pH}$ and rumen liquid volume. Br. J. Nutr. 69:385-396.

Etheridge, R. D., G. M. Pesti, and E. H. Foster. 1998. A comparison of nitrogen values obtained utilizing the Kjeldahl nitrogen and Dumas combustion methodologies (Leco CNS 2000) on samples typical of an animal nutrition analytical laboratory. Anim. Feed Sci. Technol. 73:21-28.

Ferreira, L. S., C. M. M. Bittar, V. P. Santos, W. R. S. Mattos, and A. V. Pires. 2009. Effect of inclusion of sodium butyrate, calcium propionate or sodium monensin in the starter feed on ruminal parameters and forestomach development in dairy calves. Braz. J. Anim. Sci. 38:2238-2246.

Geiger, A. J., S. H. Ward, C. C. Williams, B. J. Rude, C. J. Cabrera, K. N. Kalestch, and B. E. Voelz. 2014. Short communication: Ef- fects of increasing protein and energy in the milk replacer with or without direct-fed microbial supplementation on growth and performance of preweaned Holstein calves. J. Dairy Sci. 97:7212-7219.

Heinrichs, A. J., and B. S. Heinrichs. 2011. A prospective study of calf factors affecting first-lactation and lifetime milk production and age of cows when removed from the herd. J. Dairy Sci. 94:336-341.

Hill, T. M., J. M. Aldrich, R. L. Schlotterbeck, and H. G. Bateman. 2006. Effects of feeding calves different rates and protein concentrations of twenty percent fat milk replacers on growth during the neonatal period. Prof. Anim. Sci. 22:252-260.

Kertz, A. F., and J. R. Loften. 2013. Review: A historical perspective of specific milk-replacer feeding programs in the United States and effects on eventual performance of Holstein dairy calves. J. Dairy Sci. 29:321-332.

Khan, M. A., H. J. Lee, W. S. Lee, H. S. Kim, S. B. Kim, K. S. Ki, J. K. Ha, H. G. Lee, and Y. J. Choi. 2007. Pre - and post-weaning performance of Holstein female calves fed milk through step-down and conventional methods. J. Dairy Sci. 90:876-885.

Khan, M. A., D. M. Weary, and M. A. G. Von Keyserlingk. 2011a Invited review: Effects of milk ration on solid feed intake, weaning, and performance in dairy heifers. J. Dairy Sci. 94:1071-1081.

Khan, M. A., D. M. Weary, and M. A. G. Von Keyserlingk. 2011b. Hay intake improves performance and rumen development of calves fed higher quantities of milk. J. Dairy Sci. 94:3547-3553.

Kristensen, N. B., J. Sehested, S. K. Jensen, and M. Vestergaard. 2007. Effect of milk allowance on concentrate intake, ruminal environment, and ruminal development in milk-fed Holstein calves. J. Dairy Sci. 90:4346-4355.

Lesmeister, K. E., and A. J. Heinrichs. 2004. Effects of corn processing on growth characteristics, rumen development, and rumen parameters in neonatal dairy calves. J. Dairy Sci. 87:3439-3450.

Quigley, J. D., III. 1996. Feeding prior to weaning. Pages 245-255 in Calves, Heifers and Dairy Profitability National Conference, Harrisburg, PA. Natural Resource, Agricultural, and Engineering Service (NRAES), Cooperative Extension, Ithaca, NY.

Roth, B. A., N. M. Keil, L. Gygax, and E. Hillmann. 2009. Influence of weaning method on health status and rumen development in dairy calves. J. Dairy Sci. 92:645-656.

SAS Institute. 2013. SAS Version 9.4. SAS Inst. Inc., Cary, NC.

Silper, B. F., A. M. Q. Lana, A. U. Carvalho, C. S. Ferreira, A. P. S Franzoni, J. A. M. Lima, H. M. Saturnino, R. B. Reis, and S. G. Coelho. 2014. Effects of milk replacer feeding strategies on performance, ruminal development, and metabolism of dairy calves. J. Dairy Sci. 97:1016-1025

Silva, J. T., C. M. M. Bittar. 2013. Amino acid composition of milk replacers commercialized in Brazil. Braz. J. Anim. Sci. Vol. 41. (Abstr.)

Soberon, F., E. Raffrenato, R. W. Everett, and M. E. Van Amburgh. 2012. Preweaning milk replacer intake and effects on long-term productivity of dairy calves. J. Dairy Sci. 95:783-793.

Soberon, F., and M. E. Van Amburgh. 2013. Lactation Biology Symposium. The effect of nutrient intake from milk or milk replacer of preweaned dairy calves on lactation milk yield as adults: A metaanalysis of current data. J. Anim. Sci. 91:706-712.

Stamey, J. A., N. A. Janovick, A. F. Kertz, and J. K. Drackley. 2012 Influence of starter protein content on growth of dairy calves in an enhanced early nutrition program. J. Dairy Sci. 95:3327-3336.

Van Soest, P. J., J. B. Robertson, and B. A. Lewis. 1991. Methods for dietary fiber neutral detergent fiber, and non-starch polysaccharides in relation to animal nutrition. J. Dairy Sci. 74:3583-3597.

Weiss, W. P. 1993. Predicting energy values of feeds. In Symposium Prevailing concepts in energy utilization by ruminants. J. Dairy Sci. $76: 1802-1811$. 